\title{
Lost in translation: evidence to improve outcomes of very preterm infants
}

\author{
(9) (1) $(9)$ OPEN ACCESS \\ Vulnerable babies and their mothers are missing out on simple and effective interventions
}

\section{Peter G Davis professor and director of neonatal medicine, Louise S Owen consultant neonatologist, Brett J Manley consultant neonatologist}

Newborn Research Centre, The Royal Women's Hospital, University of Melbourne, VIC 3052, Australia

The observational study conducted by the EPICE group (doi:10. 1136/bmj.i2976) represents a huge collaborative effort and delivers an important message for those caring for the most immature newborn infants. ${ }^{1}$ As Zeitlin and colleagues point out, although the numbers of babies born in this gestational age range is relatively small, the burden of illness they and their families face is large.

The study has several important strengths. Data were collected from predefined regions rather than from individual hospitals. These regions were selected from 11 European countries and they included both public and private units. The results are therefore applicable in most developed world settings. The study was prospectively designed with parental input, and data were extensively cross checked to ensure complete ascertainment. The definitions of important morbidity would be recognised and accepted as sensible by neonatologists and parents.

It is important to recognise that the authors compared infants who received interventions (antenatal steroids) or achieved outcomes (normothermia) with infants who did not. It is not possible to comment on the intent of the caregivers. Presumably, some attempts to apply interventions were unsuccessful. The authors refer to a group of infants delivered unexpectedly or precipitously for whom provision of all four strategies may not have been possible. It is likely that many of these were infants at high risk of poor outcomes, including those born at less than 26 weeks' gestation, small for gestational age, and whose mothers were admitted on the day of birth.

The results of the study are clear and important. In a developed world setting, the uptake of a package of four simple, inexpensive measures known to improve important neonatal outcomes was surprisingly low $(<60 \%)$. Babies receiving the package had substantially better outcomes - that is, higher rates of survival without severe morbidity. The authors estimate that if uptake of the complete package were increased to $100 \%$ there would be an $18 \%$ reduction in all deaths, assuming the associations they report are causal. The results are robust and replicated using various modelling strategies. A dose-response effect is evident, as mortality increases when fewer evidence based practices are used. The authors conclude that substantial gains in survival without severe morbidity could be achieved if all eligible babies and mothers received all the evidence based interventions studied.

Neonatologists were "early adopters" of evidence based medicine, and the past decade has seen substantial growth in the conduct of well designed randomised trials. It is sobering to find such a low uptake of the simplest and most effective strategies available. The authors are careful to express their results as showing association rather than causation. They have completed the first, important part of a difficult process. To prove that implementation of these strategies causes a reduction in mortality and morbidity, effective implementation strategies need to be identified and tested in prospective randomised trials.

The gap between research findings and clinical practice is well recognised. ${ }^{2}$ Shuster and colleagues reviewed compliance with appropriate standards of care in a variety of settings. ${ }^{3}$ Their findings were similar to those of the EPICE group. Only 56\% of women underwent appropriate prenatal history, examination, and laboratory tests. Management of hip fractures was appropriate in between $67 \%$ and $95 \%$ of cases. Berenholtz and Provonost note that while considerable resources have been devoted to discovering effective treatments, more benefits are likely to come from identifying how to optimise delivery of these treatments. ${ }^{4}$ Traditionally, a crucial part of the pathway between evidence and practice has been the clinical practice guideline. A systematic review identified 76 studies describing at least one barrier to adherence to guidelines. ${ }^{5}$ Commonly, barriers affected knowledge (ie, lack of awareness or familiarity with the guidelines), attitudes (ie, lack of agreement with the evidence or differences in perception of the risk to benefit ratio), and behaviour (ie, external barriers, including insufficient time or resources). 
An overview of systematic reviews of interventions to help drive research into clinical practice makes somewhat depressing reading. ${ }^{6}$ Thirteen reviews containing 313 primary studies were identified; single interventions such as audit and feedback had only small effects. Slightly more encouraging were reviews of multifaceted interventions, which showed effect sizes ranging from small to moderate.

The EPICE group are to be congratulated on identifying an important shortfall in the uptake of neonatal evidence into practice. The next step is to develop and test interventions to overcome this shortfall and ultimately improve outcomes. Getting good evidence into practice is an urgent priority for the families of vulnerable premature babies, and for the professionals who care for them.

We acknowledge the critical review and insights of McGee Noble, change management consultant and mother of Fox who was born at 25 weeks' gestation.

Competing interests: We have read and understood the BMJ policy on declaration of interests and declare the following: none.
Provenance and peer review: Commissioned; not peer reviewed.

Zeitlin J, Manktelow BN, Piedvache A, et al. EPICE Research Group. Use of evidence based practices to improve survival without severe morbidity for very preterm infants: results from the EPICE population based cohort. BMJ 2016;353:i2976.

2 Grol R, Grimshaw J. From best evidence to best practice: effective implementation of change in patients' care. Lancet 2003;362:1225-30. doi:10.1016/S0140-6736(03)145461 pmid: 14568747.

3 Schuster MA, McGlynn EA, Brook RH. How good is the quality of health care in the United States? 1998. Milbank Q 2005;83:843-95. doi:10.1111/j.1468-0009.2005.00403.x pmid: 16279970.

4 Berenholtz S, Pronovost PJ. Barriers to translating evidence into practice. Curr Opin Crit Care 2003:9:321-5. doi:10.1097/00075198-200308000-00012 pmid:12883289.

5 Cabana MD, Rand CS, Powe NR, et al. Why don't physicians follow clinical practice guidelines? A framework for improvement. JAMA 1999;282:1458-65. doi:10.1001/jama. 282.15.1458 pmid:10535437.

6 Boaz A, Baeza J, Fraser A. European Implementation Score Collaborative Group (EIS) Effective implementation of research into practice: an overview of systematic reviews of the health literature. BMC Res Notes 2011;4:212. doi:10.1186/1756-0500-4-212 pmid: 21696585.

Published by the BMJ Publishing Group Limited. For permission to use (where not already granted under a licence) please go to http://group.bmj.com/group/rights-licensing/ permissions

This is an Open Access article distributed in accordance with the Creative Commons Attribution Non Commercial (CC BY-NC 3.0) license, which permits others to distribute, remix, adapt, build upon this work non-commercially, and license their derivative works on different terms, provided the original work is properly cited and the use is non-commercial. See: http://creativecommons.org/licenses/by-nc/3.0/. 